communicate decisions about their end-of-life care preferences. Previous research indicates that this reduces intensive medical intervention and terminal hospital admissions, leading to decreased health service costs. However, this healthcare perspective disregards the likely redistribution of costs to other public services and unpaid carers, potentially overstating the cost effectiveness of ACP. This study uses a broader societal perspective to construct a decision tree to model the costs and benefits of ACP in comparison to No ACP, and critically evaluates the appropriateness of this model in endof-life care.

Methods A decision tree was constructed consisting of three branches: participation in ACP, location of end-of-life care, and attainment of end-of-life care preferences. Values for each branch were obtained using targeted literature searching, adjustment for inflation, and assumptions based on best estimates from an expert panel. Sensitivity analysis was performed to evaluate the impact of uncertainty on the model.

Results All decisions resulted in a net cost for end-of-life care, which was not outweighed by the included benefits. However, ACP was the optimal economic decision, with a net cost of $-£$ 3,602 compared with $-£ 4,000$ for No ACP. The model was sensitive to changes in the value of informal care and the value of achieving end-of-life care preferences.

Conclusion The optimal economic decision in this study supports the upscaling of ACP in the UK. This is in keeping with previous research indicating that ACP is likely to be cost-effective, and supports the economic rationale for the current UK end-of-life care strategy. However, this should be approached sensitively, and with the understanding that the principal aim of ACP is to support patient autonomy and welfare, rather than to save money. The optimal economic decision regarding ACP is sensitive to changes in several uncertain variables. Further research is therefore required regarding the social value of informal care in the UK, and exploration of the economic value of a 'good death' as a costable benefit.

\section{P99 CHANGING EPIDEMIOLOGY AND AGE-SPECIFIC INCIDENCE OF BREAST CANCER IN ENGLAND, 1985- 2018}

Alice Miller*, Anjum Memon, Peter Bannister. Department of Primary Care and Public Health, Brighton and Sussex Medical School, Brighton, UK

\subsection{6/jech-2021-SSMabstracts. 185}

Background Although the incidence of breast cancer has been steadily increasing in most countries over the past four decades, there is an indication of stabilisation in some of the Western countries (i.e. France, Italy, Norway, USA) in recent years. We conducted a retrospective population-based cohort study to examine whether there have been changes in the incidence of breast cancer in England during the past four decades.

Methods Individual level data for women diagnosed with breast cancer in England during 1985-2018 were obtained from the Office for National Statistics/Public Health England. Average annual incidence rates were calculated by two age categories $(0-49,50+$ years $)$ during the six five-year time periods (1985-89 to 2010-14) and the recent four-year period (2015-18). The percentage change in incidence was calculated as change in the average incidence rate from the first (1985$89)$ to the last time period (2015-18).
Results During the 34-year study period, a total of 1,218,109 women with breast cancer were registered in England. In women aged 0-49 years, the average annual incidence rates increased by about $50 \%$ (from $32.6 / 100,000$ in $1985-89$ to $48.8 / 100,000$ in 2015-18); and in women aged 50+ years, the rates increased by $47 \%$ (from $241.3 / 100,000$ in 1985-89 to $355.5 / 100,000$ in $2015-18$ ). There was some indication that the rates, particularly in younger women, may be stabilising (or levelling off). With regards to the levels of deprivation, least deprived women were more likely to be diagnosed with breast cancer, compared to those who were most deprived (23.0\% versus 15.2\%).

Conclusion It appears that, like some other western countries, incidence rates of breast cancer in England, particularly among young women, may be stabilising (or levelling off). The relatively increased risk of breast cancer among least deprived women is consistent with that reported from other Western countries.

\section{P100 INTIMATE PARTNER VIOLENCE AGAINST MEN AND PRODUCTIVITY IMPACTS: EVIDENCE FROM GHANA, PAKISTAN AND SOUTH SUDAN}

${ }^{1}$ Mrinal Chadha*, ${ }^{1}$ Stacey Scriver, ${ }^{2}$ Srinivasan Raghavendran, ${ }^{3} J o h n$ Kennedy, ${ }^{1}$ Nata Durvury. ${ }^{1}$ Centre for Global Women's Studies, National University of Ireland, Galway, Ireland; '2JE Cairnes School of Business and Economics, National University of Ireland, Galway, Ireland; 3/psos MORI, London, UK

\subsection{6/jech-2021-SSMabstracts. 186}

Background Reduction of intimate partner violence (IPV) is a recognized public health goal. IPV is a significant barrier to equal participation, quality of life, and personal, social and economic development throughout the world. Relative to research on IPV against women, research on IPV against men is limited, especially in low and middle-income countries. While IPV is primarily viewed as health/human rights issue, this study explores the productivity impacts of IPV on male survivors.

Methods Employing an anonymous self-filled questionnaire, 414 male employees in Ghana, 264 male employees in Pakistan, and 357 male employees in South Sudan, working in manufacturing and services sector, were interviewed. The productivity impact of IPV on male survivors was measured using absenteeism (missing work), tardiness (getting late) and presenteeism (not being mentally present at work), subsequent to the violence experience in the last 12 months.

Results About 4 out of 10 partnered male employees in Ghana report experiencing IPV in the last 12 months (41\%). Compared to Ghana, the prevalence of IPV was lower in Pakistan (12\%) and higher in South Sudan (59\%). In Ghana, $73 \%$ of survivors report missing, on average, 5 workdays due to IPV in the last 12 months. Similarly, in Pakistan, 59\% of survivors report missing, on average, 11 workdays due to IPV, and in South Sudan, 63\% of survivors report missing, on average, 4 workdays due to IPV.

Conclusion In Ghana and South Sudan, a very high proportion of male employees report experiencing IPV in the last 12 months. Despite the prevalence of IPV being low in Pakistan, the proportion of survivors experiencing productivity impacts in very high in all countries. The results of this study suggest the need for strong intervention by businesses as the violence has productivity impacts for both male employees, which translate into significant economic costs for businesses. 